Available online on 15.05 .2017 at http://jddtonline.info
(o) 2011-17, publisher and licensee JDDT, This is an Open Access article which permits unrestricted
noncommercial use, provided the original work is properly cited

Research Article

\title{
A STUDY OF PRESCRIPTION AUDIT IN OUTPATIENT DEPARTMENT OF A TERTIARY CARE TEACHING HOSPITAL IN INDIA: AN OBSERVATIONAL STUDY
}

\author{
Pavan Kumar Kandula ${ }^{1}$, Srinivasa B Rao $^{2}$, K Sangeetha ${ }^{2}$, Y.J.V. Reddy ${ }^{2}$, Sai Krishna Gudi ${ }^{3}$ \\ ${ }^{1}$ Patient safety-Pharmacovigilance Associate, National Coordination Center, PvPI, Indian Pharmacopeia Commission, Ghaziabad, India \\ ${ }^{2}$ PES Institute of Medical Sciences and Research, Kuppam, A.P, India \\ ${ }^{3}$ Department of Pharmacy Practice, JSS college of Pharmacy, Mysore, India
}

\section{ABSTRACT}

Background: The quality of life can be improved by enhancing the standards of the medical treatment at all levels of the healthcare delivery system. A medical audit oversees the observance of these standards. Prescription Audit offers the most comprehensive overview of performance, detailing parameter as per the check list of prescription audit.

Aim: To monitor, evaluate and suggest modifications (if necessary) in the prescribing practices of medical practitioners.

Methods: The observational study was conducted over a period of 6 months and data were collected from 1093 prescriptions collected from outpatient department of a tertiary care teaching hospital in India.

Results: Total 1093 prescriptions were evaluated for the Audit, out of which 56.4\% were Male \& 43.6\% were Female cases. Majority of the study subjects belonged to the age group of 40-59 years (32.4\%). During the study mainly twelve parameter were assessed according to the checklist provided by the Hospital with total 1093 samples of prescription audit, only 2.2\% (280) cases had the non-compliance, $64.5 \%$ (8464) cases had compliance and 33.3\% (4372) not applicable to this parameters.

Conclusion: The results obtained from the study shows the prevailing prescribing habits at our institution. Many of the prescribing trends from this study are a cause of concern and need attention. This study reveals that the auditing of prescription in terms of rationality, it remains poor. The value of such audits in generating and testing hypotheses on inappropriate prescribing will definitely create an intervention to improve prescribing habits and ultimately patient care will be improved.

Keywords: Prescription Auditing, Outpatient department, Tertiary care teaching hospital, Compliance \& non-compliance.

Article Info: Received 22 March, 2017; Review Completed 13 April, 2017; Accepted 13 April, 2017; Available online May 15, 2017

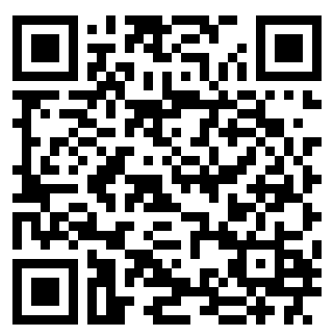

\section{Cite this article as:}

Kandula PK, Rao SB, Sangeetha K, Reddy YJV, Gudi SK, A study of prescription audit in outpatient department of a tertiary care teaching hospital in India: an observational study, Journal of Drug Delivery and Therapeutics. 2017; 7(3):92-97

DOI: http://dx.doi.org/10.22270/jddt.v7i3.1434

*Address for Correspondence

Dr. Pavan Kumar K, Patient safety-Pharmacovigilance Associate, National Coordination Center, PvPI, Indian Pharmacopeia Commission, Ghaziabad, India

Email: saipav57@gmail.com, Phone: +91-9505930107. 


\section{INTRODUCTION}

An audit is defined as the review and the evaluation of the health care procedures and documentation for the purpose of comparing the quality of care which is provided, with the accepted standards. Studying the prescribing audit is that part of the audit which seeks to monitor, evaluate and if necessary, suggest modifications in the prescribing practices of medical practitioners. Prescription audit is a quality improvement process that seeks to improve patient care. It supports health professionals in making sure their patients receive the best possible care. ${ }^{1}$

Rational drug use emphasizes on the patients' access over appropriate medication as per their clinical demand, in doses meeting their individual requirement with sufficient period of time being cost effective with them and community. ${ }^{2}$ Scope of medical audit is to evaluate the present state and future trends of drug usage, to estimate crudely the disease prevalence, drug expenditure, appropriateness of prescriptions, and adherence to evidence-based recommendations. The increasing import-ance of drug utilization studies as a valuable investigation resource in pharmacoepidemiology has been bridging it with other health-related areas such as pharmacovigilance, pharmacoeconomics, and pharmacogenetics. ${ }^{3}$

Prescription auditing has the enormous potential to promote the rational usages of drugs and essential medicine. Essential medicines are one of the vital tools needed to improve and maintain health. However, for too many people throughout the world medicines are still unaffordable, unavailable, unsafe and improperly used. $^{4}$

Potential benefits of prescription audit are as follows: ${ }^{5}$

1. Identify and promote good practice

2. Improve professional practice and quality standards
3. Supports learning and development of staff and organizations

4. Identify and eliminate poor or deficient practice

5. Identify and eliminate waste

6. Promote working with multidisciplinary teams

7. Allocate resources (financial, human) to provide better patient care

8. Develop opportunities to present findings with relevant faculty and facilitate shared learning.

\section{OBJECTIVE}

To study the Prescription Audit in Out Patient Department of a tertiary care teaching hospital.

\section{METHODOLOGY}

A prospective observational non interventional study was conducted at a tertiary care teaching hospital for a period of 6 months at PES Institute of Medical Sciences and Research, Kuppam.

\section{Study criteria:}

Inclusion Criteria:

i. Patients who attained the Out-patient Department

ii. Male \& female patients were included in the Study

\section{Exclusion Criteria:}

i. Patients who refused to take medication.

ii. Patients who were not willing to participate in the study.

\section{Source of data:}

From the Out-patient department the prescriptions file data collection, data scrutiny and statistical analysis. No patient interaction was considered, the only patients file was referred after taking prior permission from hospital authority.

Table 1: Outpatient prescription audit template (checklist)

\begin{tabular}{|c|c|c|c|}
\hline Name & Age/gender & OP no. & Department \\
\hline Date. & Time of audit & Auditor & Reviewer \\
\hline S.NO & PARAMETERS & YES & NO \\
\hline 1 & Is there any known drug allergies mentioned? & & \\
\hline 2 & Is the prescription legible? & & \\
\hline 3 & Is the drug name correctly mentioned? & & \\
\hline 4 & Is the form of the drug mentioned? & & \\
\hline 5 & Is the dose correctly mentioned? & & \\
\hline 6 & Is the route mentioned? & & \\
\hline 7 & Is the time mentioned? & & \\
\hline 8 & Presence of therapeutic duplication? & & \\
\hline 9 & $\begin{array}{l}\text { Are relevant food drug interactions (or) Drug-drug } \\
\text { interactions mentioned? }\end{array}$ & & \\
\hline 10 & Can the instructions be understood by a non medical person? & & \\
\hline 11 & Is the drug order dated, timed named and signed? & & \\
\hline 12 & Is the registration number of the doctor entered? & & \\
\hline 13 & Any other observations of note: & & \\
\hline $\begin{array}{l}\text { Signature of } \\
\text { the auditor }\end{array}$ & & & \\
\hline
\end{tabular}




\section{RESULTS AND DISCUSSION}

In this study, a total of 1093 prescriptions were evaluated over a period of six months, the demographic characteristics of the patients are shown in Figure 1. Out of 1093 patients who completed the study, majority $(56.4 \%)$ of patients were male. Majority of the study subjects belonged to the age group of 40-59 years $(32.4 \%)$.

Total twelve parameters were accessed for the prescription audit. From the table we can predict that in total 1093 samples of prescription audit, only $2.2 \%$ (280) cases had the non -compliance, $64.5 \%$ (8464) cases had compliance and $33.3 \%$ (4372) not applicable to this parameters.

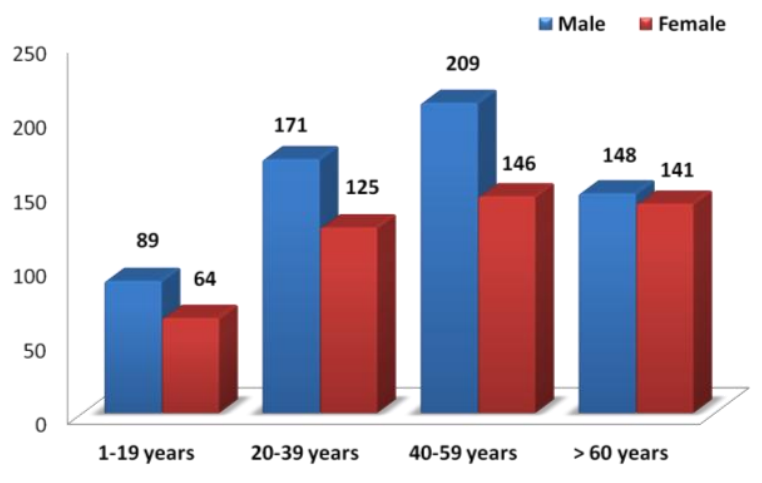

Figure 1: Age and sex distribution of the study population.

Table 2: Compliance and Non-compliance data during the Prescription Audit

\begin{tabular}{|lccc|}
\hline \multicolumn{1}{|c}{ PARAMIETERS OF PRESCRIPTION AUDIT } & YES & NO & NA \\
\hline Prescription illegibility & 1033 & 60 & 0 \\
\hline Drug dose & 1041 & 52 & 0 \\
\hline Drug allergies & 0 & 0 & 1093 \\
\hline Drug name & 1057 & 36 & 0 \\
\hline Drug dosage form & 1058 & 35 & 0 \\
\hline Prescription authentication by physician & 1061 & 32 & 0 \\
\hline Any food-drug interactions & 0 & 0 & 1093 \\
\hline Any drug-drug interactions & 0 & 0 & 1093 \\
\hline Any therapeutic duplication & 0 & 0 & 1093 \\
\hline Patient details & 1069 & 24 & 0 \\
\hline Drug frequency & 1070 & 23 & 0 \\
\hline Dispensing & 1075 & 18 & 0 \\
\hline Total counts & $\mathbf{8 4 6 4}$ & $\mathbf{2 8 0}$ & $\mathbf{4 3 7 2}$ \\
\hline \% of total counts & $\mathbf{6 4 . 5 3 \%}$ & $\mathbf{2 . 2 \%}$ & $\mathbf{3 3 . 3 \%}$ \\
\hline
\end{tabular}

During the study of 1093 cases there are mainly 12 parameters were checked according to the checklist provided by the Hospital. So there were total 13116 counts (1093x12). Out of 13116 counts, 8464 counts were compliance, 280 counts were non-compliance $\& 4372$ counts were not applicable.

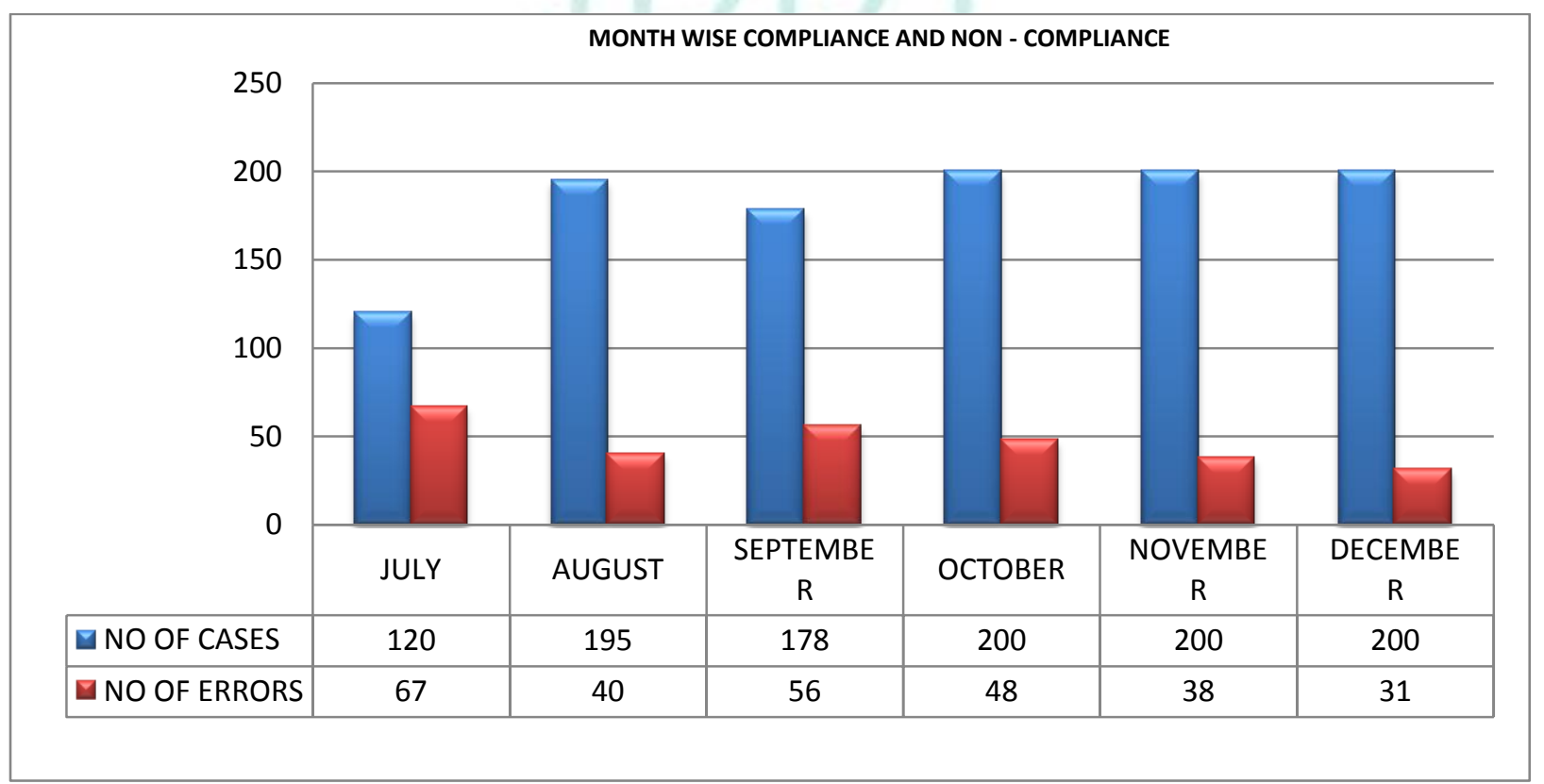

Figure 2: Month wise Compliance and Non-compliance data during prescription audit 
Figure 2 depicts monthly wise data of prescription audit, where in the month of July there were 67 errors found out of 120 cases, in the month of August there were 40 errors found out of 195 cases, in the month of September there were 56 errors found out of 178 cases, in the month of October there were 48 errors found out of 200 cases, in the month of November there were 38 errors found out of 200 cases, and in the month of December there were 31 errors found out of 200 cases.

Figure 3 shows that July month prescription audit had more number of drug dose related errors, dosage form, physician authentication errors.

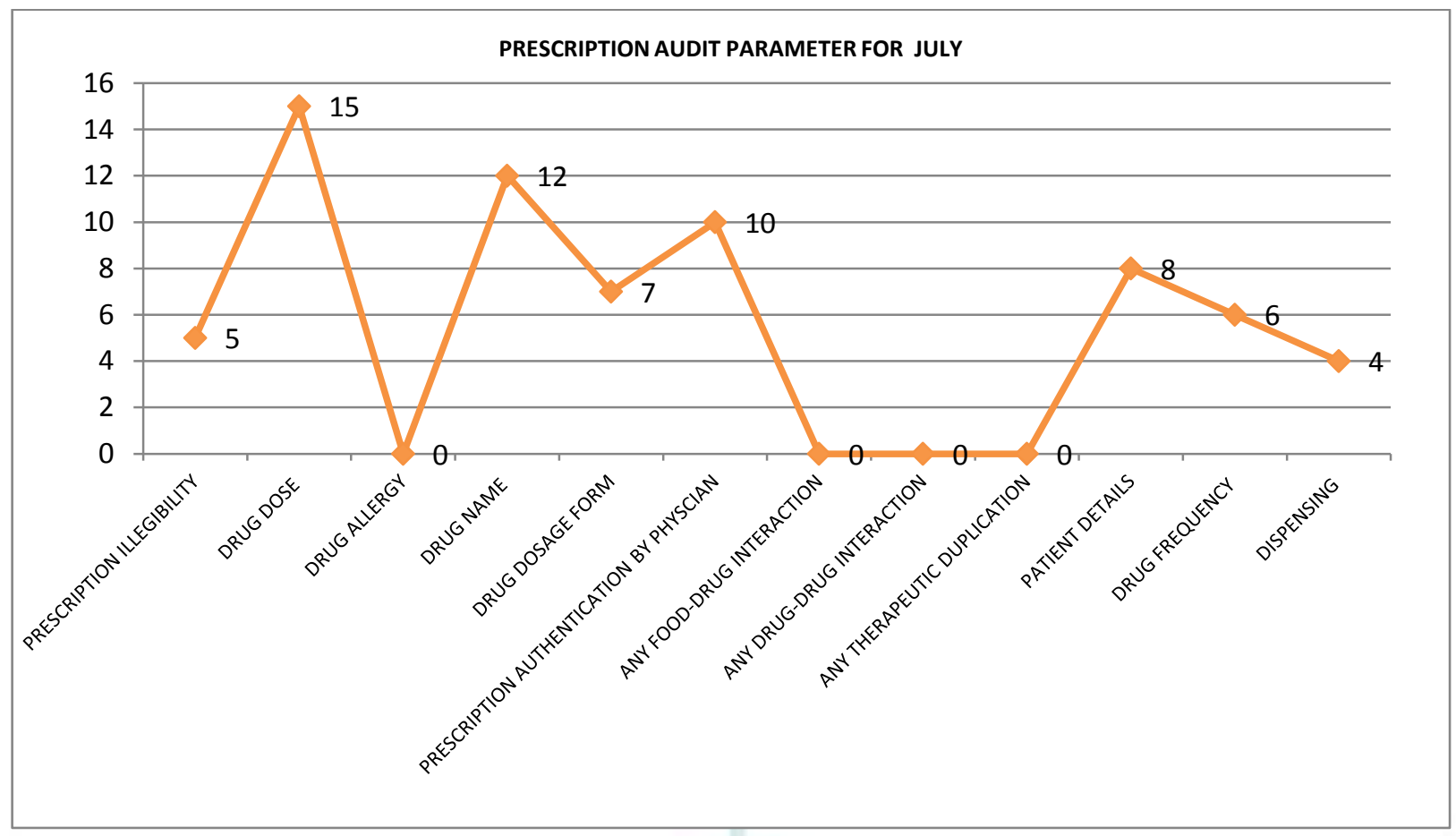

Figure 3: Study of Prescription Audit parameter for July

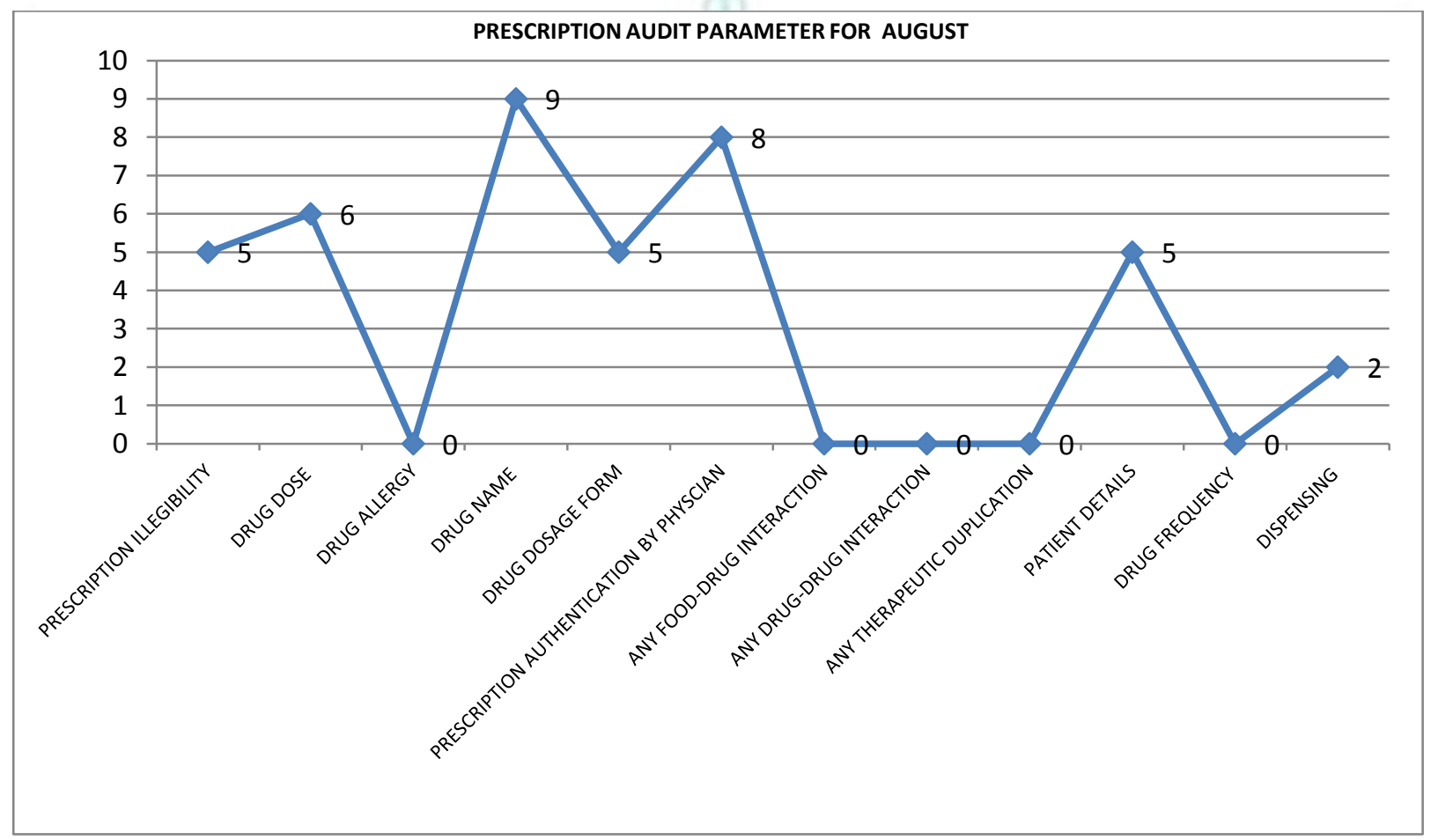

Figure 4: Study of Prescription Audit parameter for August

Figure 4 shows that August month prescription audit had more number of drug dose errors, physician authentication related errors. 


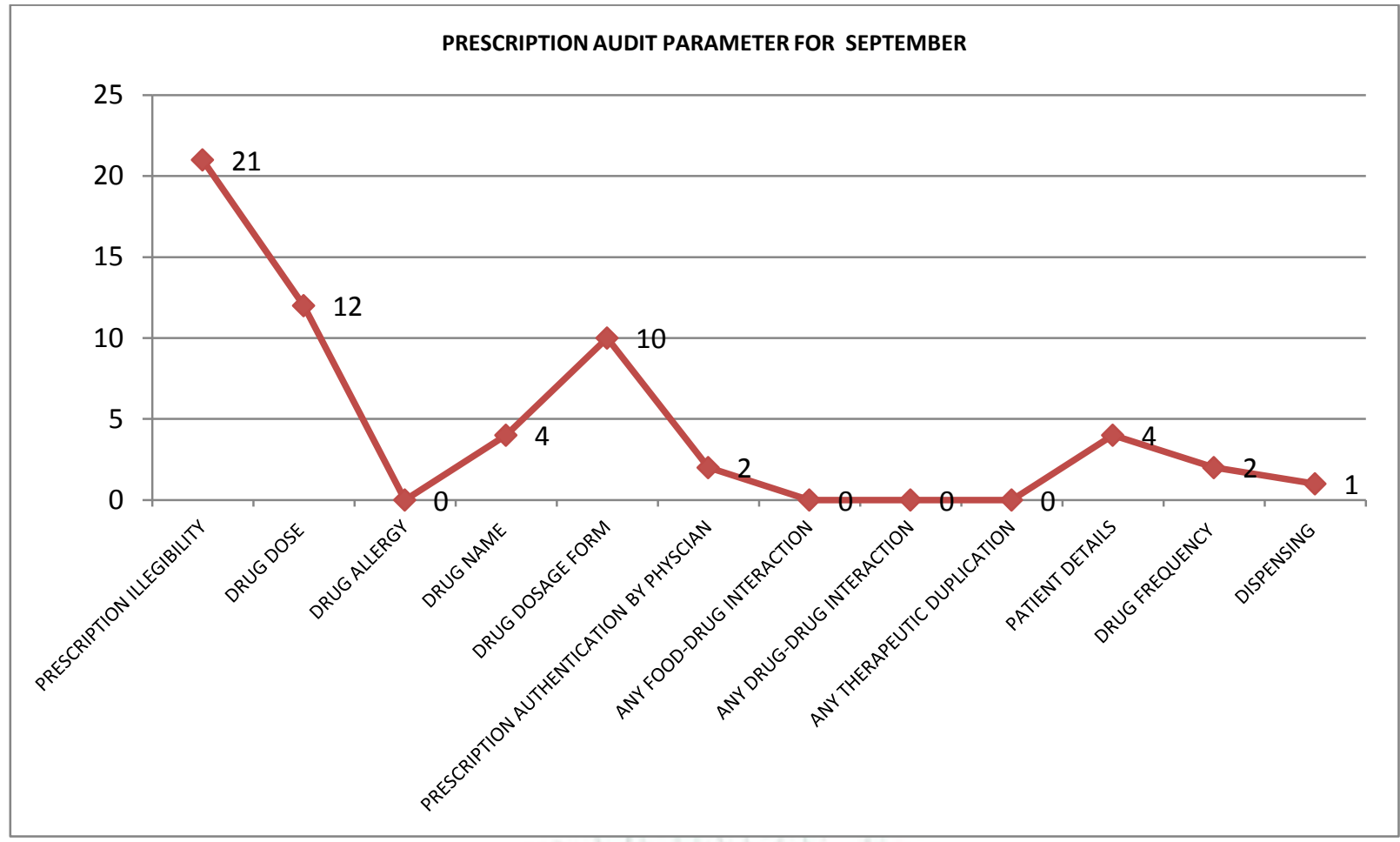

Figure 5: Study of Prescription Audit parameter for September

Figure 5 shows that September month prescription audit had more number of prescription legibility, drug dose and dosage form related errors.

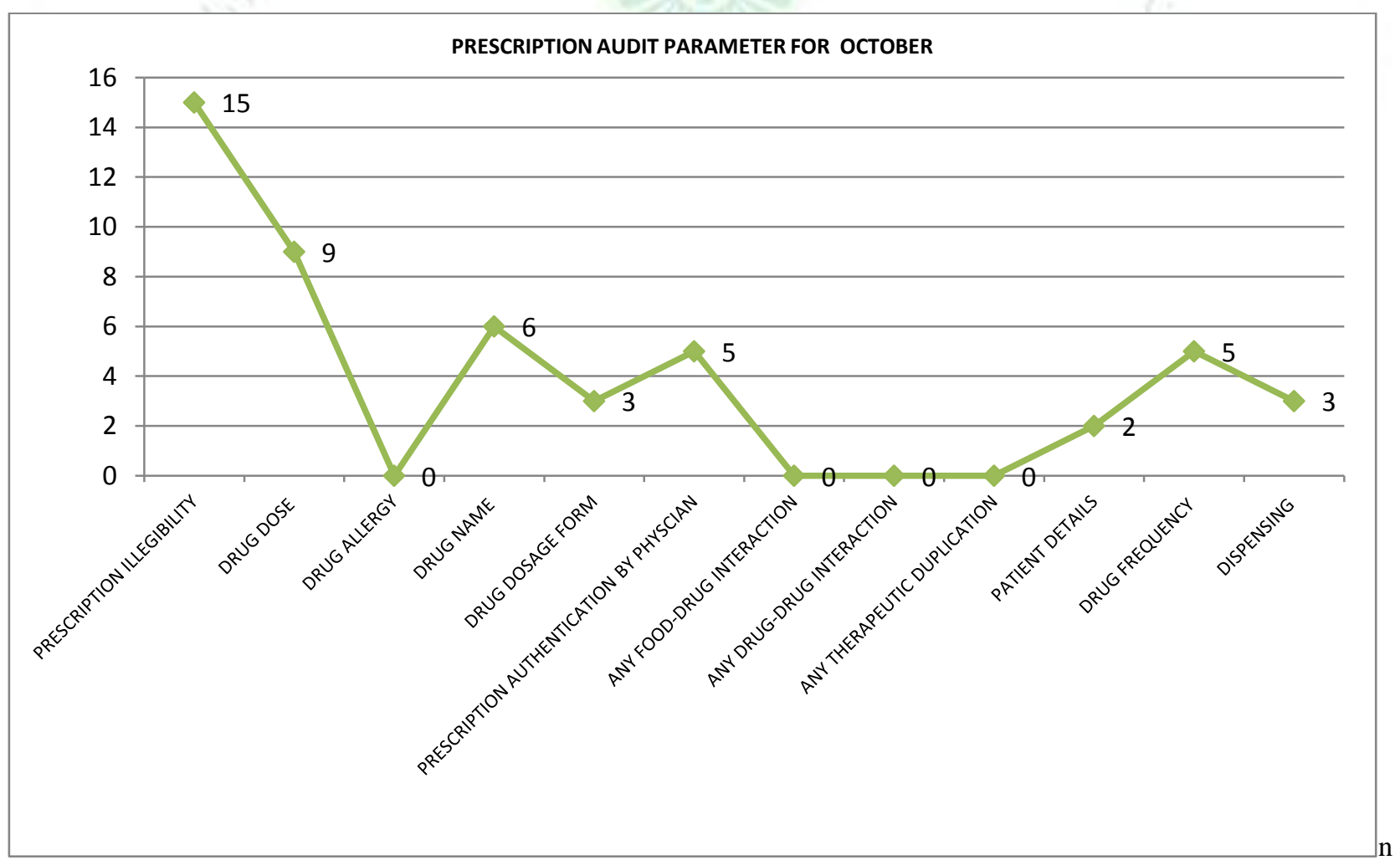

Figure 6: Study of Prescription Audit parameter for October

Figure 6 shows that October month prescription audit had more number of prescription legibility, drug dose related errors.

Figure 7 shows that November month prescription audit had more number of prescription legibility, drug dose related errors. 


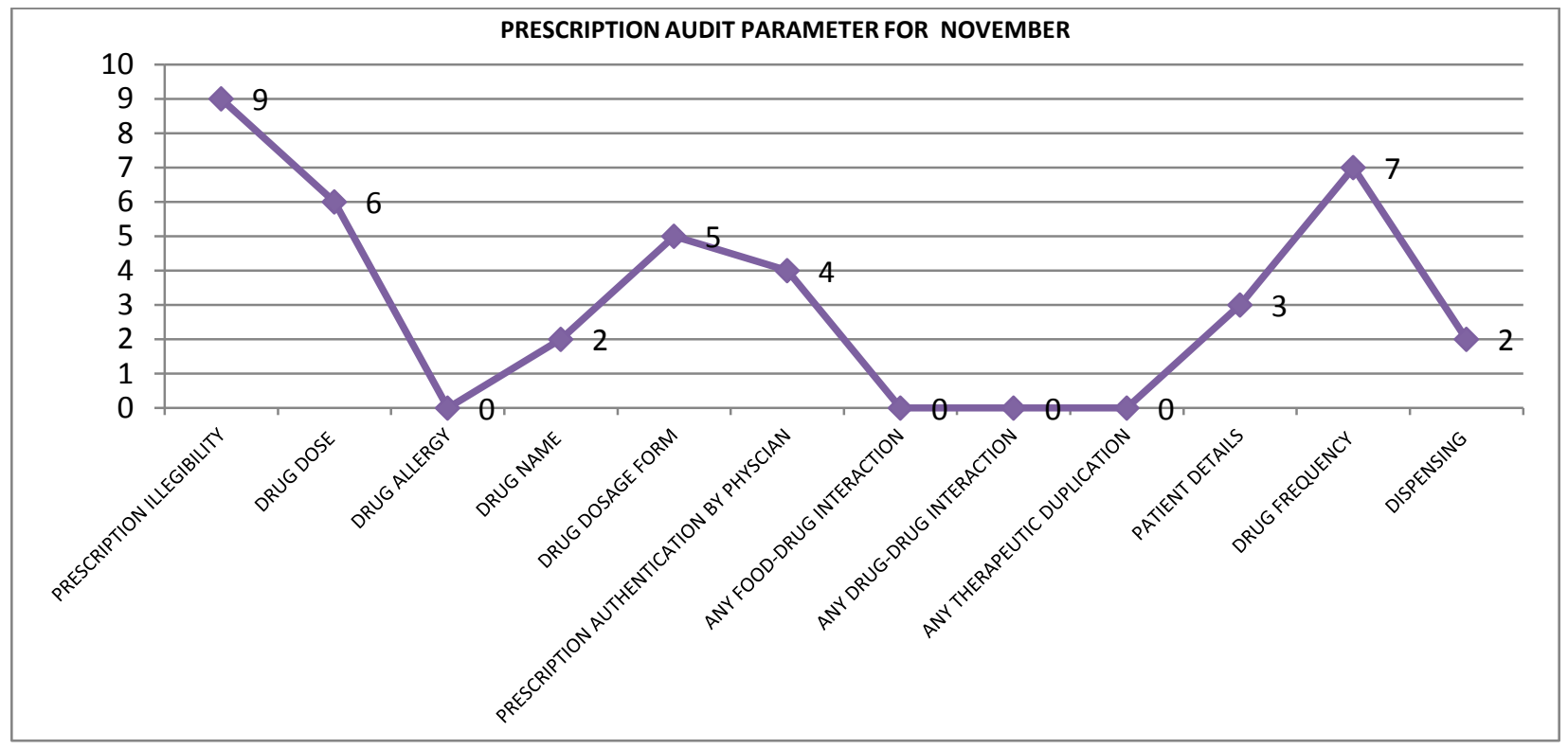

Figure 7: Study of Prescription Audit parameter for November

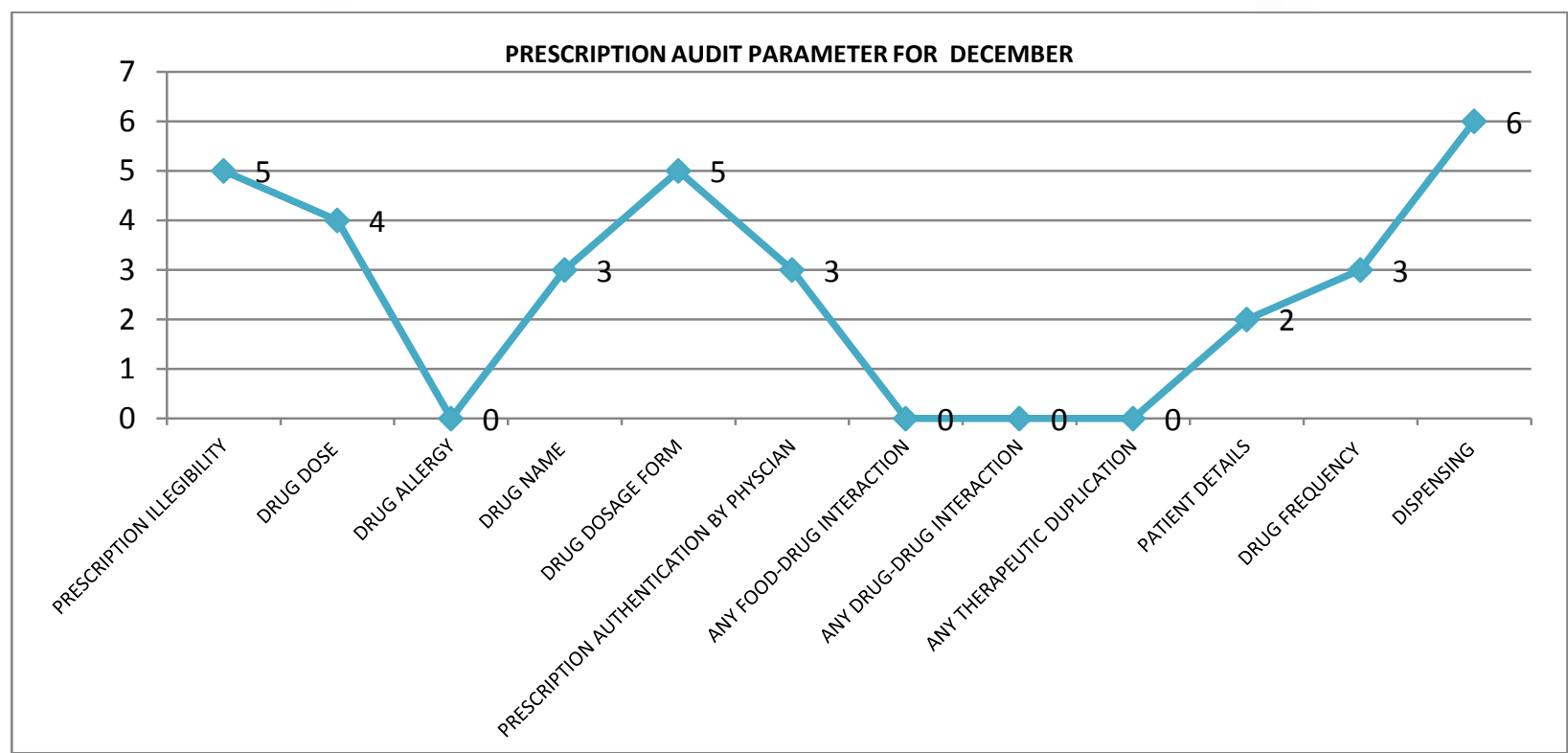

Figure 8: Study of Prescription Audit parameter for December

Figure 8 shows that December month prescription audit had more number of dispensing, prescription legibility related errors.

\section{CONCLUSION}

As per this study, compliance rate of prescription audit parameters was $64.53 \%$, which has to be improved by regular training of staff and conducting large team meetings and small team meetings with clinicians in organization. Month wise study showed that numbers of the non-compliance in prescription audit was reduced from 67 (in the month of July 2015) to 31 (in the month of December 2015). This is mainly due to the hospital management has implemented the suggestion provide by clinical Pharmacist.

\section{REFERENCES}

1. Grass F. Drug utilization therapy and practice: the present situation in Federal Republic of Germany. Eur J Clin Pharmacol 1981; 19:387-94.

2. Hussain S, Parveen Z, Gupta S, Kumar D, Gupta R, Thakur S. A study of prescription auditing in rural health care setting of north India. Int J Med Sci Public Health 2016; 5: 2461-65.

3. Fresle DA, Wolfheim C (1997). Public education in rational drug use: a global survey. Geneva, World Health Organization.

4. Hepler CD, Strand LM. Opportunities and responsibilities in pharmaceutical care. Am J Hosp Pharm. 1990; 47(3):533-43.

5. Curtis P. Medical audit in general practice. J R Coll Gen Pract. 1974; 24(146):607-11.

6. Patterson HR. The problems of audit and research. J R Coll Gen Pract. 1986; 36(286): 196.

7. Jyoti N, Kaur S. To analyze the Impact of Serial Prescription Audits with Active Feedback on Quality of Prescription Behaviour. J Clin Diagn Res. 2013; 7(4):680-83. 